\title{
Hierarchical trade and endogenous price distortions
}

Working Paper

Author(s):

Gersbach, Hans; Haller, Hans

Publication date:

2007-08

Permanent link:

https://doi.org/10.3929/ethz-a-005425709

Rights / license:

In Copyright - Non-Commercial Use Permitted

Originally published in:

Economics Working Paper Series 07/72 


\section{CER-ETH - Center of Economic Research at ETH Zurich}

\section{Hierarchical Trade and Endogenous Price Distortions}

Hans Gersbach and Hans Haller

Working Paper 07/72

August 2007

\section{Economics Working Paper Series}

\section{EIH}

Eidgenössische Technische Hochschule Zürich Swiss Federal Institute of Technology Zurich 


\title{
Hierarchical Trade and Endogenous Price Distortions*
}

\author{
Hans Gersbach ${ }^{\dagger}$ and Hans Haller ${ }^{\ddagger}$
}

First version: July 2000

This Version: September 2007

\begin{abstract}
We study the allocation of commodities through a two-stage hierarchy of competitive markets. Groups or countries trade at global prices while individuals within a group trade at local prices. We identify the free trade and the autarky equilibrium as polar cases. We show that no other two-stage market equilibria exist if the commodity space is two-dimensional. An example demonstrates that other, so-called intermediate equilibria exist for three-dimensional commodity spaces. The example also exhibits endogenous price distortions in third countries when some countries follow distortionary trade policies. We give two existence proofs for intermediate equilibria in higher dimensions. Each proof provides an explicit construction of special classes of intermediate equilibria.
\end{abstract}

*We thank Clive Bell, Switgard Feuerstein, David Orden, Till Requate and seminar participants in Heidelberg and Virginia Tech for insightful comments. Hans Haller gratefully acknowledges the hospitality and support of ETH Zurich, Chair of Macroeconomics: Innovation and Policy (MIP).

${ }^{\dagger}$ CER-ETH - Center of Economic Research at ETH Zurich, Zürichbergstrasse 18, 8092 Zurich, Switzerland

${ }_{\ddagger}^{\ddagger}$ Department of Economics, Virginia Polytechnic Institute and State University, Blacksburg, VA 24061-0316, USA 


\section{Introduction}

Resources allocation mechanisms have often a hierarchical structure. The simplest case is a two-stage mechanism where goods are first allocated among groups of agents and then allocated among the individuals in each group. For instance, multi-member households may participate as entities in markets and decide on the distribution of the consumption bundles within the household afterwards. The most prominent example is provided by international trade where the groups are nations and the individuals are consumers and producers. Individuals in a nation face a domestic price system. At the same time, overall trade balances among nations are equalized at global price systems which may differ from the local prices, if significant barriers to international trade exist in the form of tariffs and quantitative restrictions that drive a wedge between local and global prices. Trade within and between trading blocks such as the European Union and NAFTA constitutes another example of a two-stage allocation scheme - with countries playing the role of individuals (agents). Finally, many governmental (political, public) decision processes follow a hierarchical pattern, distinguishing between "internal" and "external" decisions, between local (regional) and global (central) levels as well. ${ }^{1}$

The aim of this paper is to study in a general equilibrium framework the simultaneous allocation of commodities through a two-stage hierarchy of competitive markets. Members of a group of people (a household, nation, etc.) trade within the group at an internal price system. However, internal markets need not be cleared and the group can act as a trading block vis-àvis the rest of the world. The group's trade with the rest of the world occurs through an external trade agency at an external price system. Balancing of

\footnotetext{
${ }^{1}$ For recent contributions on fiscal federalism, see Cassella and Frey (1992), Persson and Tabellini (1996). Concerning international affairs and negotiations, see Putnam (1988), Haller and Holden (1997).
} 
the group's external trade budget and market clearing across groups have to be achieved at the external price system. Internal and external prices can differ since we assume that goods arbitrage across groups is limited. ${ }^{2}$ We focus on the classical issues, such as equilibrium existence, Pareto efficiency and the nature of inefficiencies in hierarchical market systems. Moreover, we explore the relationship between trade in a single market and trade in hierarchical market systems. We further provide an explanation for endogenous price distortions.

We begin by devising a framework to study hierarchical market equilibria where groups trade at the global price system while individuals within a group trade at local price systems. Then we identify the free trade and the autarky equilibrium as polar cases. As a rule, free trade yields efficient allocations of commodities whereas autarky leads to inefficient allocations. Therefore, the question arises if there is the possibility of an intermediate outcome that Pareto dominates an autarky equilibrium allocation, but which itself is Pareto dominated by some other feasible allocation, though not necessarily by an equilibrium allocation. ${ }^{3}$

In the main part of the paper, we aim for existence results for intermediate equilibria. A first finding indicates that equilibria that are intermediate to free trade and autarky generally do not exist, even under standard assumptions that guarantee competitive equilibria within each group of the economy. We show that essentially no other market equilibria than free trade and autarky exist if the commodity space is two-dimensional: The world is divided into a free trade zone and an autarky zone. An example demon-

\footnotetext{
${ }^{2}$ Limitations to goods arbitrage can result from tariff or non-tariff barriers, transportation costs or through differences in market power across groups. See e.g. Verboven (1996) for a recent study on why car prices differ so much even between European countries and Lutz (2004) for the specific role of arbitrage barriers in the car market.

${ }^{3}$ While the search for such equilibria motivates our inquiry, the "intermediate equilibria" investigated in the sequel may not satisfy the suggested Pareto rankings.
} 
strates that intermediate equilibria exist for three-dimensional commodity spaces. The example also introduces endogenous price distortions: Suppose a proper subset of countries follow distortionary trade policies that drive a wedge between local and world market prices. Then in two-stage market equilibria, price distortions can arise in other countries as well. Hence observed differences between local and global prices in one country may be related to distortionary trade policies in other countries. In contrast, when trade takes place in one market place, distortions deliberately introduced in a subset of countries do not lead to price distortions in other countries. They only affect global market prices.

We go on to provide two existence proofs for intermediate equilibria in higher dimensions. They also show how one can construct special classes of intermediate equilibria. First, if the number of economic groups is at least three and smaller than the number of goods traded, an intermediate equilibrium can be constructed by dividing the economy into two distinct exchange economies. The existence proof can easily be extended to type economies. Second, if the dimension of the commodity space is at least three and the market demand of every group can be generated as the demand function of its representative consumer, intermediate equilibria can be shown to exist and can be constructed by restricting trade in a particular good within each group.

Following the foregoing agenda, the paper is organized as follows. In the next section, we relate the paper to the literature. In sections 3 and 4 , we introduce the formal framework. In particular, we define two-stage market equilibria. Free trade and autarky are identified as the polar cases. In section 5 we show that no intermediate equilibrium exists if the dimension of the commodity space is two. In section 6 , we analyze an example with three consumers and three commodities with an explicitly calculated two-stage market 
equilibrium, which is intermediate in the sense that the allocation, though inefficient, Pareto dominates the initial endowment allocation (autarky in this case). In section 7 , we establish existence of intermediate equilibria by using two different methods of constructing intermediate equilibria. In section 8 , we discuss the relationship between trade in single and in dual market places. Section 9 concludes.

\section{Relation to the Literature}

The paper is related to models of international trade with price distortions. In these models, domestic consumers and producers in a nation face a set of domestic prices. The domestic price vector differs from the world prices by a set of country specific trade taxes, levied on the net imports of the tradeable commodities. It is well known from the theory of the second best that elimination of part of the distortions need not improve welfare. A number of authors derive conditions under which a gradual multi-lateral reform of tariffs would cause a Pareto improvement. Hatta and Fukushima (1979) give conditions under which a proportional decrease of ad valorem tariffs in all countries improves welfare in a world with two goods and two countries. Fukushima and Kim (1989) and Turunen-Red and Woodland (1991) extend the analysis to arbitrary numbers of goods and countries. Turunen-Red and Woodland (1991) apply these results to various tariff reform proposals such as proportional reductions in tariffs and the reduction of the highest ad valorem tariff rates. Yun (1995) shows that there is a unique continuous path of allocations from a distortionary equilibrium to the optimum that can be followed by proportional changes of price distortions.

In this paper, we develop a hierarchical model of international trade. The trade literature assumes that all nations and their constituents trade in a single market place, though each nation may face a different price system due to tariffs or subsidies. We view trade within and trade among groups 
as activities that take place in two different market places. Consumers in a group trade at local prices whereas the group's trade with the rest of the world occurs in a global market place and at a global price system. Each individual faces a budget constraint when trading in the local market place. In addition, the group faces a budget constraint when trading in the global market place. We shall demonstrate that different market places for global and local trade and, consequently, double budget constraints play an important role for equilibrium existence, the occurrence of price distortions and welfare considerations.

A significant body of empirical literature has shown that large differences in the prices of tradeable goods, such as cars, are a persistent phenomenon across countries and even within Europe [e.g. Flam (1992), Verboven (1996)]. In some of these cases, international price discrimination cannot be linked to the existing tariff and non-tariff barriers [see Verboven (1996)]. Lutz (2004) identifies arbitrage barriers in the car market as a main reason why prices differ across countries. Arbitrage barriers can arise from transaction costs and search costs. We show that some of the price differences can occur endogenously. If in a two stage market setting certain countries follow distortionary trade policies, such price distortions can spill over to other countries. Therefore, internal prices may differ from global prices even in countries where no distortionary policies have been implemented. This is quite different from trade in one market place. There, distortions introduced by some countries do not lead to price distortions in other countries.

It is well known from the study of allocation under uncertainty and the comparison of complete versus incomplete markets that the difference between single and multiple budget constraints is a significant one. In our framework, markets are complete from an individual's perspective in that the individual can trade all commodities (assets). Markets are also com- 
plete, yet distorted, in inter-group trade. Considering the favorite setting of conventional trade theory, a two-dimensional commodity space, we observe a stark contrast between single and double budget constraints. Yun (1995) obtains a continuous path from a distortionary equilibrium to the optimum. We obtain a dichotomy, either autarky or free tree, and consequently the absence of a continuous path between the two.

\section{Two-Stage Market Allocations}

We consider a model of a finite pure exchange economy where commodities, consumer characteristics and allocations are standard. The distinguishing feature of the model is the allocation mechanism, a two-stage hierarchy of markets.

\subsection{Commodities, Consumers, and Allocations}

There exists a finite number $\ell \geq 1$ of commodities. Thus the commodity space is $\mathbb{R}^{\ell}$. Each commodity is a private good.

There is a finite population of consumers or individuals, represented by a set $I$. A generic consumer is denoted by $i$ or $j$. Each consumer $i \in I$ has consumption set $X_{i}=\mathbb{R}_{+}^{\ell}$. The endowment of $i$ is a commodity bundle $w_{i} \in \mathbb{R}_{++}^{\ell}$. For a given price system $p \in \mathbb{R}^{\ell}, B_{i}(p)=\left\{x_{i} \in X_{i} \mid p x_{i} \leq p w_{i}\right\}$ denotes $i$ 's budget set. Individual $i$ has continuous, convex and monotonic preferences on $X_{i}$ represented by a utility function $U_{i}: X_{i} \longrightarrow \mathbb{R}$.

An allocation of commodities assumes the form $\mathbf{x}=\left(x_{i}\right)_{i \in I}$ and belongs to the allocation space $\mathcal{X} \equiv \prod_{j \in I} X_{j}$. In $\mathbf{x} \in \mathcal{X}$, the consumption bundle $x_{i} \in X_{i}$ is assigned to individual $i \in I$. 


\subsection{Groups and Two-Stage Markets}

The population $I$ is partitioned into groups or nations, i.e. there exists a partition $P$ of $I$ into non-empty subsets. $P$ has generic elements $h$ and consists of $H$ groups frequently labelled $h=1, \ldots, H$. For each group $h \in P$, set $\mathcal{X}_{h}=\prod_{i \in h} X_{i}$, the consumption set for group $h$. $\mathcal{X}_{h}$ has generic elements $\mathbf{x}_{\mathbf{h}}=\left(x_{i}\right)_{i \in h}$. If $\mathbf{x} \in \mathcal{X}$ is a commodity allocation, then consumption for group $h$ is $\mathbf{x}_{\mathbf{h}}=\left(x_{i}\right)_{i \in h}$, the restriction of $\mathbf{x}=\left(x_{i}\right)_{i \in I}$ to $h$. Thus group $h$ attains the group consumption $\mathbf{x}_{\mathbf{h}} \in \mathcal{X}_{h}$. We set $w_{h} \equiv \sum_{i \in h} w_{i}$, the social endowment of group $h$.

Next we define two-stage market equilibria. The definition is based on the given partition $P$ of the consumer population $I$ into groups.

Def.: A two-stage market equilibrium is a tuple $\left(p ;\left(q_{h}\right)_{h \in P} ; \mathbf{x}\right)$ such that

(1) $p \in \mathbb{R}^{\ell}$ is an external (global, world) price system;

(2) $q_{h} \in \mathbb{R}^{\ell}$ is an internal (local, domestic) price system for each $h \in P$;

(3) $\mathbf{x}$ is an allocation of commodities to consumers;

(4) $x_{i} \in \arg \max \left\{U_{i}\left(y_{i}\right) \mid y_{i} \in B_{i}\left(q_{h}\right)\right\}$ for each individual $i \in I$ and household (group, country) $h \in P$ with $i \in h$;

(5) $p \cdot\left(\sum_{i \in h} x_{i}-\sum_{i \in h} w_{i}\right) \leq 0$ for each $h \in P$;

(6) $\sum_{i \in I} x_{i}=\sum_{i \in I} w_{i}$.

The central idea is that individuals can only trade freely within their group (household, country) $h$, taking the internal price system $q_{h}$ as given. This 
condition is formalized as (4). Under our assumptions on preferences, individual budget constraints are binding and Walras' Law holds group by group:

(7) $q_{h} z_{h}=0$

where $z_{h} \equiv \sum_{i \in h} x_{i}-\sum_{i \in h} w_{i}$ is the group's aggregate excess demand. The fact that individuals can only trade within their respective group does not necessarily mean that the group's internal market has to be cleared. Rather the group $h$ as a trading block can have a non-zero net trade $z_{h}$ with the rest of the world. In external trade, the group takes the external price system $p$ as given and is subject to an external budget constraint. This condition is reflected in (5). Finally, (6) is the formal expression of the global market clearing condition. Conditions (5) and (6) imply for each group $h$ balancing of its external trade account:

(8) $p z_{h}=0$.

Note that the equilibrium allocation of a group has to satisfy two budget constraints: the budget constraint with respect to the local prices that enter the individual budgets, giving rise to (7), and a second budget constraint with respect to global prices, giving rise to (8). This reflects our view of trade in two different market places.

From the perspective of traditional trade theory, our investigation can be viewed as an exploration of the feasibility and consequences of balanced trade combined with revenue-neutral tariffs cum subsidies in a two-stage market environment. For suppose the government of country $h$ imposes tariffs cum subsidies reflecting the price differential $q_{h}-p$. This gives rise to a government revenue of $\left(q_{h}-p\right) z_{h}$. In a two-stage market equilibrium, each country balances its external trade account, that is (8) holds and satisfies Walras' Law, that is (7) holds as well. Hence the tariffs cum subsidies are revenue-neutral: 
(9) $\left(q_{h}-p\right) z_{h}=0$.

Obviously, any two of the conditions (7) - (9) imply the third one. Next let us discuss two conceivable deviations from these conditions.

(a) In theory and in practice, it is not necessarily the case that the balanced trade condition (8) holds. A country may incur a trade deficit, $p z_{h}>0$, or a trade surplus, $p z_{h}<0$. If (7) still holds for each country, then the country's government makes a gain (loss) of $\left(q_{h}-p\right) z_{h}=-p z_{h}$ equal to its trade surplus (deficit). To dispose of such gains and losses in a way that maintains (7), the gainers might simply finance the losers' trade deficits. The international credit market would be balanced, since by $(6), \sum_{h} z_{h}=0$, and hence $\sum_{h} p z_{h}=0$.

(b) Perhaps the most frequently made suggestion on the utilization of government tariff revenue is to distribute it in a lump-sum fashion among the constituents of the country. More precisely, the government net tariff revenue will be channeled to consumers as lump-sum transfers or will be raised by lump-sum taxes in the case of net subsidies. This, however, requires to modify the individual budget constraints accordingly. Aggregate income of the country's consumers is augmented by $\left(q_{h}-p\right) z_{h}$ so that $q_{h} z_{h}=\left(q_{h}-p\right) z_{h}$ or $p z_{h}=0$. This shows that the lump-sum tariffs or taxes lead to balanced trade and a government revenue of $q_{h} z_{h}$ in equilibrium. Our equilibrium concept requires that $q_{h} z_{h}=0$ whereas conventional trade theory (in what we call a single market equilibrium) allows for $q_{h} z_{h} \neq 0$. In the sequel, we shall treat the latter as our benchmark case. The exact relationship between two-stage market equilibria and single market equilibria (one-stage market equilibria) will be further delineated in Sections 6 and $8 .^{4}$

\footnotetext{
${ }^{4}$ In Gersbach and Haller (2007), we extend the notion of two-stage equilibria to the case $q_{h} z_{h} \neq 0$ (and $p z_{h} \neq 0$ ) and we provide a formal definition of a one-stage market equilibrium.
} 
In our model, a country satisfies both (7) and (8) in equilibrium. The world economy operates under a system of tariffs cum subsidies that gives rise to balanced trade. Countries could also be interpreted as a priori isolated islands which each have their own domestic market. One can then ask what would happen, if each island decided to participate in inter-island trade provided that this turned out to be revenue-neutral for the island government and balanced the island's external trade account. The result would be a two-stage market equilibrium.

Our general assumptions guarantee the existence of Walrasian equilibria for an economy. Assuming strictly positive endowments and monotonic, convex, and continuous preferences for each individual consumer suffices. Ensuring equilibrium existence facilitates the discussion of efficiency of twostage market equilibria. Moreover, the assumptions on preferences imply that all individuals and groups exhaust their budgets and hence the budget balancing conditions (7) and (8) hold.

\section{Free Trade and Autarky}

To begin with, we can state the following proposition for non-trivial $P$, i.e. $1<|P|<|I|:$

Proposition 1 For generic consumer characteristics, there are at least two two-stage market equilibria, one of which is Pareto optimal and the other one is not.

\section{Proof:}

For a proof, we construct a "free trade equilibrium" which is Pareto optimal and an "autarky equilibrium" which is not Pareto optimal.

Free Trade Equilibrium: Under our standard assumptions, there exists a Walrasian equilibrium $(\hat{p} ; \hat{\mathbf{x}})$ for the entire economy. Set $\hat{q}_{h}=\hat{p}$ for $h \in P$, and 
$\hat{\mathbf{x}}=\left(\hat{x}_{i}\right)_{i \in I}$. Then $\left(\hat{p} ;\left(\hat{q}_{h}\right)_{h \in P} ; \hat{\mathbf{x}}\right)$ is a two-stage market equilibrium and $\hat{\mathbf{x}}$ is a Pareto-optimal allocation. At such a "free trade equilibrium", individual consumers maximize their utility subject to external prices. Since $\hat{x}_{i} \in B_{i}(\hat{p})$ for each $i \in I$, each group $h$ meets its budget constraint.

Autarky Equilibrium: Also under standard assumptions, there exists a Walrasian equilibrium $\left(q_{h}^{*} ; x_{h}^{*}\right)$ for the sub-economy formed by the members of any group $h \in P$. Now fix a family $\left(q_{h}^{*} ; x_{h}^{*}\right), h \in P$, of such "local" equilibria, choose an arbitrary $p^{*} \in \mathbb{R}^{\ell}$ and set $\mathbf{x}^{*}=\left(x_{i}^{*}\right)_{i \in I}$. Then $\left(p^{*} ;\left(q_{h}^{*}\right)_{h \in P} ; \mathbf{x}^{*}\right)$ constitutes a two-stage market equilibrium. More specifically, it is an "autarky equilibrium" where each group has zero external trade:

$$
\sum_{i \in h} x_{i}^{*}-\sum_{i \in h} w_{i}=0 \quad \text { for all } \quad h \in P
$$

As a rule, the internal equilibrium price systems $q_{h}^{*}, h \in P$, are not collinear and the equilibrium allocation $x^{*}$ is not Pareto-optimal.

The existence of these two particular equilibria establishes the claim of the proposition. (q.e.d.)

\section{The Two-Dimensional Case}

After having established two distinguished types of equilibria - a free trade equilibrium that is Pareto-optimal and an autarky equilibrium - an obvious question is whether there is room for intermediate degrees of equilibrium inefficiencies and how their properties differ from trade with price distortions in a single market place. As will become clear, the existence and nature of intermediate equilibria depends crucially on the dimension of the commodity space. We first examine exchange economies with two goods that are reminiscent of most of the classical international trade models. 
Proposition 2 Suppose $\ell=2$. Then, at a two-stage market equilibrium with $p \gg 0$, the world is divided into an autarkic trade zone and a free trade zone. One of the zones may be empty.

\section{Proof:}

Because of our preference assumptions a two-stage market equilibrium requires

$$
\begin{aligned}
q_{h} x_{i} & =q_{h} w_{i} ; \\
p \sum_{i \in h} x_{i} & =p \sum_{i \in h} w_{i} ; \\
\sum_{i \in I} x_{i} & =\sum_{i \in I} w_{i} .
\end{aligned}
$$

Hence, we also have

$$
q_{h} \sum_{i \in h}\left(x_{i}-w_{i}\right)=p \sum_{i \in h}\left(x_{i}-w_{i}\right)=0
$$

If $\sum_{i \in h} x_{i} \neq \sum_{i \in h} w_{i}$, then both $q_{h}$ and $p$ are orthogonal to $\sum_{i \in h}\left(x_{i}-w_{i}\right) \neq 0$; hence they are collinear. But since $p \gg 0$ and $q_{h}>0$, this implies that the two price systems are identical up to normalization. Therefore with prices restricted to the unit simplex, $\sum_{i \in h} x_{i}=\sum_{i \in h} w_{i}$ (autarky) or $q_{h}=p$ (free trade) prevails for each country $h$. (q.e.d.)

Thus, with a two-dimensional commodity space, no intermediate equilibria exist, except possibly equilibria that divide the world into an autarkic and a free trade zone. This conclusion has been reached independently by Bell (2003, p. 50f) who argues in terms of the government budget: "In the two-good case considered here, which wholly conforms to the textbook case, imposing a tariff while denying the government the use of lump-sum transfers [to achieve zero net revenue] can only be done if there are no transactions to tax." This is in sharp contrast to classical international trade theory, where the existence of competitive equilibria is guaranteed under general 
conditions [see e.g. Dixit and Norman (1980)] even when significant, but not totally prohibitive, barriers to international trade exist in the form of tariffs and non-tariff restrictions.

The contrast between single and double budget constraints is further accentuated by the existence and non-existence, respectively, of a continuous path from autarky to free trade. Ideally, one would like to trace a continuous path from an inefficient, distorted equilibrium (e.g. autarky) to the optimal free trade equilibrium, perhaps even continuously improving welfare along the path. With single budget constraints, Yun (1995) shows that, indeed, a unique path can be constructed, beginning at a distortion equilibrium, going through proportional changes of price distortions, and ending at the targeted optimum. With double budget constraints, the non-existence of intermediate equilibria rules out any path between the two polar outcomes.

\section{An Example}

Before we establish the existence and nature of intermediate equilibria for three- or higher-dimensional commodity spaces, we illustrate the concepts with an example. The example will also illuminate the relationship between trading in a single market place and trading in two market places and will exhibit the occurrence of endogenous price distortions. Suppose $\ell=3,|I|=H=3$. Thus, each group contains exactly one individual. For every individual $i$ the utility function is given by

$$
U_{i}=U_{h}=\frac{1}{3} \ln \left(x_{h}^{1}\right)+\frac{1}{3} \ln \left(x_{h}^{2}\right)+\frac{1}{3} \ln \left(x_{h}^{3}\right), \quad i=h=1,2,3
$$


$x_{h}^{k}$ denotes the consumption of the $\mathrm{k}$-th good by individual $h$. The endowments are given by

$$
\begin{aligned}
& w_{1}=(1,0,0) ; \\
& w_{2}=(0,1,0) ; \\
& w_{3}=(0,0,1) .
\end{aligned}
$$

The autarky solution leaves every individual with his endowments. Due to symmetry, it is obvious that free trade is characterized by $p^{1}=p^{2}=p^{3}=1$ and

$$
\begin{aligned}
& x_{1}=\left(\frac{1}{3}, \frac{1}{3}, \frac{1}{3}\right), \\
& x_{2}=\left(\frac{1}{3}, \frac{1}{3}, \frac{1}{3}\right), \\
& x_{3}=\left(\frac{1}{3}, \frac{1}{3}, \frac{1}{3}\right) .
\end{aligned}
$$

To calculate an intermediate equilibrium, we normalize prices so that $p^{1}=$ $1, q_{1}^{1}=1, q_{2}^{2}=1, q_{3}^{3}=1$. $q_{h}^{k}$ denotes the local price for good $k$ in group $h$. The corresponding excess demand vector amounts to

$$
\begin{aligned}
& z_{1}=\left(-\frac{2}{3}, \frac{1}{3 q_{1}^{2}}, \frac{1}{3 q_{1}^{3}}\right) ; \\
& z_{2}=\left(\frac{1}{3 q_{2}^{1}},-\frac{2}{3}, \frac{1}{3 q_{2}^{3}}\right) ; \\
& z_{3}=\left(\frac{1}{3 q_{3}^{1}}, \frac{1}{3 q_{3}^{2}},-\frac{2}{3}\right) .
\end{aligned}
$$

Market clearing and the global budget constraint yield:

$$
\begin{aligned}
q_{2}^{1}+q_{3}^{1} & =2 q_{2}^{1} q_{3}^{1} \\
q_{1}^{2}+q_{3}^{2} & =2 q_{1}^{2} q_{3}^{2} \\
q_{1}^{3}+q_{2}^{3} & =2 q_{1}^{3} q_{2}^{3} \\
p_{2} q_{1}^{3}+p_{3} q_{1}^{2} & =2 q_{1}^{2} q_{1}^{3} \\
q_{2}^{3}+p_{3} q_{2}^{1} & =2 p_{2} q_{2}^{3} q_{2}^{1} \\
q_{3}^{2}+p_{2} q_{3}^{1} & =2 p_{3} q_{3}^{1} q_{3}^{2}
\end{aligned}
$$


Let us choose $q_{1}^{2}=2, q_{1}^{3}=3$. Solving the system of equations immediately yields $q_{3}^{2}=\frac{2}{3}, q_{2}^{3}=\frac{3}{5}$ and the remaining equations as:

$$
\begin{aligned}
q_{2}^{1}+q_{3}^{1} & =2 q_{2}^{1} q_{3}^{1} \\
3 p_{2}+2 p_{3} & =12 \\
3+5 p_{3} q_{2}^{1} & =6 p_{2} q_{2}^{1} \\
2+3 p_{2} q_{3}^{1} & =4 p_{3} q_{3}^{1}
\end{aligned}
$$

$p_{3}=\frac{5}{2}, p_{2}=\frac{7}{3}, q_{3}^{1}=\frac{2}{3}, q_{2}^{1}=2$ is a solution of this reduced system. The resulting intermediate equilibrium allocation is:

$$
\begin{aligned}
& x_{1}=\left(\frac{1}{3}, \frac{1}{6}, \frac{1}{9}\right) \\
& x_{2}=\left(\frac{1}{6}, \frac{1}{3}, \frac{5}{9}\right) \\
& x_{3}=\left(\frac{1}{2}, \frac{1}{2}, \frac{1}{3}\right)
\end{aligned}
$$

This allocation differs from autarky and free trade. Thus, the allocation together with the global and local prices constitute an intermediate equilibrium. Note that the third individual is better off in the intermediate equilibrium than under free trade. However, the allocation in the intermediate equilibrium is not Pareto-efficient. Individuals would like to trade again in one market place, starting from the allocations they received in the intermediate equilibrium.

The example can also be used to demonstrate the differences and similarities between traditional trade theory in single market places and the perspective of hierarchical trade in local and global market places. Let us denote the price distortion of the local price for commodity $k$ in group $h$ by $\tau_{h}^{k}:$

$$
\tau_{h}^{k}=\frac{q_{h}^{k}}{p^{k}}-1
$$


$\tau_{h}^{k}$ can be positive or negative. In traditional trade theory, the price distortion is often related to the existence of tariffs, subsidies, quantitative restrictions, transportation costs, search costs, imperfect competition or nonconvertibility of currencies. Let us denote the distortion vector of country $h$ by $\tau_{h}=\left(\tau_{h}^{1}, \tau_{h}^{2}, \tau_{h}^{3}\right) . \tau^{k}=\left(\tau_{1}^{k}, \tau_{2}^{k}, \tau_{3}^{k}\right)$ is the distortion vector of good $k$. In our example, the commodity distortion vectors amount to:

$$
\begin{aligned}
\tau^{1} & =\left(0,1,-\frac{1}{3}\right) \\
\tau^{2} & =\left(-\frac{1}{7},-\frac{4}{7},-\frac{5}{7}\right) \\
\tau^{3} & =\left(\frac{1}{5},-\frac{19}{25},-\frac{3}{5}\right)
\end{aligned}
$$

The corresponding country distortion vectors amount to:

$$
\begin{aligned}
\tau_{1} & =\left(0,-\frac{1}{7}, \frac{1}{5}\right) \\
\tau_{2} & =\left(1,-\frac{4}{7},-\frac{19}{25}\right) \\
\tau_{3} & =\left(-\frac{1}{3},-\frac{5}{7},-\frac{3}{5}\right)
\end{aligned}
$$

Obviously, the intermediate equilibrium also defines an equilibrium in which nations trade in one market place, while domestic consumers face the domestic prices $q_{h}^{k}=p^{k}\left(1+\tau_{h}^{k}\right)$.

We assume that the distortions represent tariffs and subsidies and the government net tariff revenue will be channeled to consumers as lump-sum transfers or will be raised by lump-sum taxes in the case of net subsidies. We claim that the intermediate equilibrium has a companion single market equilibrium with the same distortions $\tau_{h}^{k}$ and the same allocations. This follows from the following observations. At distortions $\tau_{h}^{k}$ and global prices $p^{k}$ of the intermediate equilibrium domestic consumers choose an excess demand equal to that in the intermediate equilibrium if lump-sum transfers were zero. And thus markets would clear. But since $\sum_{k=1}^{3} p^{k}\left(x_{h}^{k}-w_{h}^{k}\right)=0$ and 
$\sum_{k=1}^{3} q_{h}^{k}\left(x_{h}^{k}-w_{h}^{k}\right)=0$ for all countries, in the intermediate equilibrium we have

$$
\sum_{k=1}^{3} \tau_{h}^{k} p^{k}\left(x_{h}^{k}-w_{h}^{k}\right)=0 .
$$

Therefore, at equilibrium distortions and global prices of the intermediate equilibrium, the government budget is balanced in the single market equilibrium and thus lump-sum transfers are indeed zero which validates our assertion. Obviously, the companion single-market equilibrium can be derived directly by fixing the price distortions and solving for the equilibrium prices and allocations.

Intermediate equilibria require a budget constraint at global prices that is absent from trade in one market place. While an intermediate equilibrium has an associated single-market place equilibrium, the situation changes and becomes more complex if we start with existing wedges between local and global prices. In many cases, some of the distortions $\tau_{h}^{k}$ are given exogenously, due to trade policy or trade frictions such as transportation costs. As soon as certain distortions are introduced exogenously, trading in one market place and trading in two market places may yield different results with respect to consumption allocation and prices as well as with respect to distortions. Three cases can occur.

CASE 1: There does not exist a corresponding intermediate equilibrium. Suppose e.g. nation $h=1$ introduces tariffs and subsidies corresponding to the distortion vector

$$
\tau_{1}=\left(-\frac{1}{2}, \frac{1}{2}, \frac{1}{2}\right)
$$

The other countries face no distortions: $\tau_{2}=(0,0,0)$ and $\tau_{3}=(0,0,0)$. We first derive the equilibrium in the single market case. We denote the vector of world prices by $p^{0}=\left(1, p_{2}^{0}, p_{3}^{0}\right)$ where we have normalized prices so that $p_{1}^{0}=1$. We denote by $L S T_{h}$ the lump-sum individual $h$ receives (or pays if 
$\left.L S T_{h}<0\right)$ in country $h$. The Marshallian demand functions for country 1 are then given as follows:

$$
\begin{aligned}
& x_{1}^{1}=\frac{2}{3} L S T_{1}+\frac{1}{3} \\
& x_{1}^{2}=\frac{2 L S T_{1}+1}{9 p^{2}} ; \\
& x_{1}^{3}=\frac{2 L S T_{1}+1}{9 p^{3}} .
\end{aligned}
$$

Then, there exists a unique single market equilibrium with price system $p^{0}=$ $\left(1, \frac{3}{5}, \frac{3}{5}\right)$ and equilibrium allocation

$$
\begin{aligned}
& x_{1}^{0}=\left(\frac{3}{5}, \frac{1}{3}, \frac{1}{3}\right), \\
& x_{2}^{0}=\left(\frac{1}{5}, \frac{1}{3}, \frac{1}{3}\right), \\
& x_{3}^{0}=\left(\frac{1}{5}, \frac{1}{3}, \frac{1}{3}\right) .
\end{aligned}
$$

Equilibrium lump-sum transfers are given by $L S T_{1}=\frac{2}{5}, L S T_{2}=0, L S T_{3}=0$. Note that

$$
L S T_{1}=\sum_{k=1}^{3} \tau_{1}^{k} p^{k}\left(x_{h}^{k}-w_{h}^{k}\right)=\frac{2}{5}
$$

for any set of world market prices $p^{0}=\left(1, p_{2}^{0}, p_{3}^{0}\right)$. From this observation we can infer that there does not exist an intermediate market equilibrium if the first country imposes the distortions $\tau_{1}=\left(-\frac{1}{2}, \frac{1}{2}, \frac{1}{2}\right)$ even if we allow for any suitable distortion vectors in the other countries. An intermediate equilibrium with budget constraints at the local and global level would require that the expression $\sum_{k=1}^{3} \tau_{1}^{k} p^{k}\left(x_{h}^{k}-w_{h}^{k}\right)$ is equal to zero which can never hold since terms are positive as soon as we depart from autarky.

Thus, intermediate equilibria put constraints on the set of feasible distortions even for a single country. For an intermediate equilibrium to exist, it must be possible that variations in world market prices lead to budget 
balance which, equivalently, requires that $L S T_{h}$ is equal to zero in the associated single market equilibrium. One can easily show that in our example no intermediate equilibrium exists if $L S T_{h}$ is different from zero for at least one country in the single market equilibrium. This is, however, a property of Cobb-Douglas utility functions and of the endowment distribution in our example where $L S T_{h}$ is either constant or a linear function of one world market price.

CASE 2: A subset of countries introduces distortions an intermediate equilibrium exists with the same distortions in these countries, but different distortions in other countries and a different equilibrium allocation. Such equilibria require distortions in those countries which have not introduced them. Suppose e.g. that nations $h=1$ and $h=2$ introduce tariffs and subsidies corresponding to the distortion vectors

$$
\begin{aligned}
& \tau_{1}=(0,-1 / 7,1 / 5) \\
& \tau_{2}=(1,-4 / 7,-19 / 25) .
\end{aligned}
$$

Consider trading in a single market place first. Thus, the third country faces no distortions: $\tau_{3}=(0,0,0)$. World prices are given by $p^{0}=\left(1, p_{2}^{0}, p_{3}^{0}\right)$, where $p_{1}^{0}=1$. A single market place equilibrium in the traditional sense treats all distortions as exogenous, i.e. it imposes three constraints, the third given by $\tau_{3}=(0,0,0)$. Again, the government net tariff revenue will be channeled to consumers as lump-sum transfers or will be raised by lump-sum taxes in the case of net subsidies. In this particular case, lump-sum transfers are zero at any set of world market prices. Market clearing for the first two commodities yields

$$
\begin{aligned}
-\frac{2}{3}+\frac{p_{2}^{0}\left(1+\tau_{2}^{2}\right)}{3\left(1+\tau_{2}^{1}\right)}+\frac{p_{3}^{0}}{3} & =0 \\
-\frac{2}{3}+\frac{1+\tau_{1}^{1}}{3 p_{2}^{0}\left(1+\tau_{1}^{2}\right)}+\frac{p_{3}^{0}}{3 p_{2}^{0}} & =0 .
\end{aligned}
$$

Inserting the distortion vectors for nations $h=1,2$ yields the following pair 
of equations:

$$
\begin{array}{r}
28-3 p_{2}^{0}-14 p_{3}^{0}=0 \\
12 p_{2}^{0}-7-6 p_{3}^{0}=0
\end{array}
$$

Solving for $p_{2}^{0}, p_{3}^{0}$ yields a vector of world prices $p^{0}=\left(1, \frac{133}{93}, \frac{105}{62}\right)$ and the equilibrium allocation amounts to

$$
\begin{aligned}
& x_{1}^{0}=\left(\frac{1}{3}, \frac{31}{114}, \frac{31}{189}\right) ; \\
& x_{2}^{0}=\left(\frac{19}{186}, \frac{1}{3}, \frac{95}{189}\right) ; \\
& x_{3}^{0}=\left(\frac{35}{62}, \frac{15}{38}, \frac{1}{3}\right) .
\end{aligned}
$$

Let us consider trading in two market places next. Then $\tau_{3}$ is treated as endogenous. The set of equilibrium prices has to fulfill equations (11)-(16). (14)-(16) express the balancing of external trade accounts that is not required in a single market equilibrium. Moreover, the relationship between local and global prices is given by $q_{h}^{k}=\left(1+\tau_{h}^{k}\right) p^{k}, k=1,2,3 ; h=1,2$. We normalize prices so that $p_{1}=1, q_{1}^{1}=1, q_{2}^{2}=1, q_{3}^{3}=1$. Solving for $q_{3}^{1}$ (equation (11)), $q_{3}^{2}$ (equation (12)), $p_{2}$ and $p_{3}$ (equations (14) and (15)) yields a uniquely determined price vector

$$
\begin{aligned}
q_{1} & =(1,2,3), \\
q_{2} & =\left(2,1, \frac{3}{5}\right), \\
q_{3} & =\left(\frac{2}{3}, \frac{2}{3}, 1\right) ; \\
p & =\left(1, \frac{7}{3}, \frac{5}{2}\right)
\end{aligned}
$$

It is the same as in the previous intermediate equilibrium. The allocations coincide with the allocations in equations (21)-(23). Thus, the single market place equilibrium has a companion intermediate equilibrium. But the equilibrium allocations and the distortions differ: The single-market place equilibrium does not imply distortions in the country without an exogenously 
given distortion vector, whereas the intermediate equilibrium does.

The example illustrates a fundamental property of intermediate equilibria: Suppose a proper subset of countries follow distortionary trade policies that drive a wedge between local and world market prices. Then price distortions arise in other countries as well. In the example, local prices in the third country deviate from global prices by an even larger margin than in the countries that caused the distortions. Hence, observed differences between local and global prices in one country may be caused by distortionary trade policies in other countries. In contrast, when trade takes place in one market place, distortions deliberately introduced in a subset of countries do not lead to price distortions in other countries. ${ }^{5}$ They only affect global market prices. In sum, the organization of trade matters in the presence of exogenous partial price distortions. If a subset of countries employs trade tariffs or non-tariff barriers to trade, the resulting equilibrium allocations depend on whether trade takes place in one or two market places.

CASE 3: A single market equilibrium has an associated intermediate equilibrium with the same distortions in all countries and the same allocation. Suppose again that nations $h=1$ and $h=2$ introduce tariffs and subsidies according to

$$
\begin{aligned}
\tau_{1} & =\left(0,-\frac{1}{7}, \frac{1}{5}\right), \\
\tau_{2} & =\left(1,-\frac{4}{7},-\frac{19}{25}\right)
\end{aligned}
$$

where again $\tau_{3}=(0,0,0)$ in the third country. Therefore, the same singlemarket equilibrium as before is realized.

\footnotetext{
${ }^{5}$ With a single budget constraint, "domestic distortions" in the sense of Anderson et al. (1995), i.e. a wedge between domestic producer and consumer prices, will not spill over to other countries either.
} 
Consider trading in two market places where the relationship between local and global prices is again given by

$$
q_{h}^{k}=\left(1+\tau_{h}^{k}\right) p^{k}, \quad k=1,2,3 ; h=1,2
$$

We normalize prices differently than before by setting $p_{1}=1, q_{1}^{1}=1, q_{22}=$ $\frac{19}{31}, q_{3}^{1}=1$. Running through market clearing conditions and budget constraints at world prices yields a uniquely determined price vector:

$$
\begin{aligned}
q_{1} & =\left(1, \frac{38}{31}, \frac{63}{31}\right), \\
q_{2} & =\left(2, \frac{19}{31}, \frac{63}{155}\right), \\
q_{3} & =\left(1, \frac{133}{93}, \frac{105}{62}\right), \\
p & =\left(1, \frac{133}{93}, \frac{105}{62}\right) .
\end{aligned}
$$

World market prices and distortions in all countries coincide with those in the single market equilibrium. The allocation is the same as in the single market equilibrium. Therefore, intermediate market equilibrium and single market equilibrium coincide with respect to distortions, world market prices and allocations.

\section{$7 \quad$ Existence of Intermediate Equilibria}

In this section we establish existence of intermediate equilibrium allocations for three- or higher dimensional commodity spaces. The propositions also demonstrate how one can construct special classes of intermediate equilibria. In order to avoid pathological cases we assume throughout this section that autarky and free trade differ and that under free trade, each group has a nonzero net trade and each individual attains a strictly positive consumption bundle.

Proposition 3 Suppose $\ell \geq 4$ and $2<H<\ell$. Then an intermediate twostage equilibrium exists for generic consumer characteristics. 


\section{Proof:}

Let $x_{h}\left(q_{h}\right)=\sum_{i \in h} x_{i}\left(q_{h}\right)$ for $h \in P, q_{h} \in \mathbb{R}_{+}^{\ell}$ denote the aggregate demand vector of group $h$ at prices $q_{h}$. Finally, denote the excess demand of group $h$ at prices $q_{h}$ by $z_{h}\left(q_{h}\right)=x_{h}\left(q_{h}\right)-w_{h}$. Let us divide the set of groups $P$ into two non-empty subsets $P^{1}$ and $P^{2}\left(P=P^{1} \cup P^{2}\right)$. Consider two pure exchange economies $E^{1}$ and $E^{2}$. In $E^{1}\left(E^{2}\right)$ consumers belong to groups in $P^{1}\left(P^{2}\right)$, respectively. Take two corresponding equilibria with price vectors $\mathfrak{p}^{1}$ and $\mathfrak{p}^{2}$ and allocations denoted by $\mathbf{x}_{\mathbf{P}^{1}}$ and $\mathbf{x}_{\mathbf{P}^{2}}$. Generically, $\mathfrak{p}^{1}$ or $\mathfrak{p}^{2}$ differs from both autarky and full trade prices. Consider for each group $h$ the orthogonal complement of the equilibrium excess demand vector

$$
c_{h}^{\perp}=\left\{y_{h} \in \mathbb{R}^{\ell} \mid y_{h} \cdot z_{h}\left(\mathfrak{p}^{1}\right)=0 \text { if } h \in P^{1}, y_{h} \cdot z_{h}\left(\mathfrak{p}^{2}\right)=0 \text { if } h \in P^{2}, \text { resp. }\right\} .
$$

In general, $c_{h}^{\perp}$ has dimension $\ell-1$ or dimension $\ell$. Consider the intersection $\bigcap_{h} c_{h}^{\perp}$ taken over all groups $h$ in $P$. This intersection has at least dimension 1 since we have at most $\ell-1$ orthogonal complements (as $H<\ell$ ) and one intersection operation reduces the dimension at most by one. Now take any vector $p \neq 0$ in $\bigcap_{h} c_{h}^{\perp}$. We claim that $\left(p ;\left(q_{h}=\mathfrak{p}^{1}\right)_{h \in P^{1}},\left(q_{h}=\mathfrak{p}^{2}\right)_{h \in P^{2}} ; \mathbf{x}_{\mathbf{P}^{1}}, \mathbf{x}_{\mathbf{P}^{2}}\right)$ is a two-stage market equilibrium. $\mathfrak{p}^{1}$ and $\mathfrak{p}^{2}$ generate local price systems for the corresponding groups. Moreover, $\left(\mathbf{x}_{\mathbf{P}^{1}}, \mathbf{x}_{\mathbf{P}^{2}}\right)$ is an allocation of commodities. By construction, we have $p \cdot\left(\sum_{i \in h} x_{i}-\sum_{i \in h} w_{i}\right)=0$. Since market clearing prevails for both sub-economies $P^{1}$ and $P^{2}$, overall market clearing follows. (q.e.d.)

Caveat: In general, the foregoing proof does not yield non-negative world market prices! Since countries themselves do not optimize, negative prices do not pose a problem per se, but — as a referee has noted - are counterfactual in a model with monotone preferences.

Proposition 3 can easily be extended to type economies. A type economy in our context is defined as follows. Two groups are of the same type if their excess demand function is identical. The most natural case occurs when 
both groups contain the same number of individuals and each individual in one group has an identical counterpart with respect to endowments and preferences in the other group. We obtain

Proposition 4 Suppose $\ell \geq 3$, and $M$ types of groups with $2 \leq M<\ell$. Then, generically, an intermediate two-stage equilibrium exists.

\section{Proof:}

We can apply the same construction as in Proposition 3 with one additional consideration. When dividing the economy into two non-empty subsets, all groups of the same type have to be put into one exchange economy. Then, we have at most $\ell-1$ different orthogonal complements of the equilibrium consumption vector, since each group of the same type has the same equilibrium vector. Again, by considering the intersection of all complements, we can find the global prices. (q.e.d)

Proposition 5 Suppose $\ell>2$ and that all groups are singletons. Suppose further for each $i \in I$, that interior consumption bundles are preferred to exterior ones and that the utility function is concave and differentiable in the interior of $X_{i}$. Then, generically, intermediate equilibria exist.

Proof: Here we identify individual $i$ with group $\{i\}$ and, accordingly, label both individuals and groups by $h=1, \ldots, H$.

Consider the following exchange economy, denoted by $E$. Individual $h$ is allowed to trade except in one arbitrarily chosen commodity $k_{h}$. Consider a corresponding equilibrium of $E$, denoted $\left(p, \mathbf{x}^{*}\right)$. For each individual $h$, let

$$
q_{h}=\operatorname{grad} U_{h}\left(\mathbf{x}_{\mathbf{h}}^{*}\right)
$$

Then, $q_{h}$ is a supporting price system for group (individual) $h$ at $\mathbf{x}_{\mathbf{h}}^{*} \gg 0$. We claim that $\left(p ;\left(q_{h}\right)_{h \in P} ; \mathbf{x}^{*}\right)$ is an intermediate two-stage equilibrium. We first 
observe that $p$ and $q_{h}$ typically differ. Since generically, each group has a nonzero net trade under free trade, we can choose the commodity in which group $h$ is not allowed to trade in $E$, so that the excess demand $\mathbf{x}_{\mathbf{h}}^{*}-\omega_{h}$ differs from that under free trade. Hence, the allocation under free trade is different from $\mathbf{x}^{*}$. Clearly, $\mathbf{x}^{*}$ is an allocation of commodities. Since $\ell>2$, and every group is only restricted in trading of one commodity groups, as a rule, have nonzero net trades with the rest of the world in the exchange economy $E$. Thus the allocation $\mathbf{x}^{*}$ also differs from autarky. The incorporation of the nontradeable commodity into the budget constraint does not matter in $E$ and, therefore, we have $p \cdot z_{h}^{*}=0$ for the group's excess demand $z_{h}^{*}=\sum_{i \in h}\left(x_{i}^{*}-\omega_{i}\right)$.

In the next step we show that $q_{h} z_{h}^{*}=0$. Suppose that group $h$ is not allowed to trade in commodity $k_{h} \in\{1, \ldots, \ell\}$ in the exchange economy $E$. Because of $\mathbf{x}_{\mathbf{h}}^{*} \gg 0$ and the hypothesized properties of the utility functions, there exists a scalar $\lambda_{h}>0$ such that

$$
\frac{\partial U_{h}\left(\mathbf{x}_{\mathbf{h}}^{*}\right)}{\partial x_{h}^{k}}=\lambda_{h} p^{k} \quad \text { for } k \neq k_{h} .
$$

Equation (30) characterizes the first-order conditions for an interior competitive equilibrium in $E$. Furthermore,

$$
\frac{\partial U_{h}\left(\mathbf{x}_{\mathbf{h}}^{*}\right)}{\partial x_{h}^{k}}=q_{h}^{k} \quad \text { for all } \mathrm{k} .
$$

Hence, we obtain:

$$
q_{h} z_{h}^{*}=q_{h}^{k_{h}} z_{h}^{* k_{h}}+\lambda_{h} \sum_{k \neq k_{h}} p^{k} z_{h}^{* k}=0 .
$$

The first term is zero because group $h$ did not trade in commodity $k_{h}$. The second term is zero since this represents the budget constraint of group $h$ in the exchange economy $E$. Finally, market clearing is guaranteed since all groups participate in the exchange economy E. Thus $\left(p,\left(q_{h}\right)_{h \in P} ; \mathbf{x}^{*}\right)$ is an intermediate equilibrium, that is a two-stage market equilibrium with the desired properties: no group enjoys (quasi-)free trade or autarky. (q.e.d) 
Notice that in the intermediate two-stage market equilibrium constructed in the proof, all commodities are tradeable, despite the fact that the construction is based on an artificial economy $E$ where every group cannot trade a specific commodity $k_{h}$.

In traditional international trade theory, the central results such as the law of comparative advantage and Heckscher-Ohlin theorems are sensitive to dimensionality and survive only as correlations or in an average sense in higher dimensions. Existence of equilibria including distortions is, however, not sensitive to dimensionality [see e.g. Ethier (1984)]. For trade in two market places, dimensionality is decisive. We obtain non-trivial intermediate equilibria only for three- or higher dimensional commodity spaces. Since extensive empirical work suggests that low dimensionality may be inadequate (Leamer and Levinsohn 1995), we expect such intermediate equilibria to exist as a rule.

We have phrased the central existence theorem in terms of one-person groups. However, the existence result can be extended to groups containing an arbitrary number of consumers, as long as there exists a representative consumer for each group such the aggregate demand function of each group is generated by the demand function of its representative consumer. Then we can apply the same arguments as above to establish the existence of intermediate equilibria for groups with an arbitrary number of individuals. 


\section{Hierarchical Trade versus Trade in One Mar- ket Place}

Hierarchical trade differs from traditional trade theory in terms of the organization of markets. However, as already suggested in the example, an equivalence between the set of two-stage market equilibria and the set of single-market equilibria exists in terms of distortions. Let us denote the price distortion for commodity $k$ in group $h$, for a given intermediate equilibrium $\left(p ;\left(q_{h}\right)_{h \in P} ; \mathbf{x}\right)$ by $\tau_{h}^{k}$. Thus:

$$
\tau_{h}^{k}=\frac{q_{h}^{k}}{p^{k}}-1
$$

Moreover, let $\tau_{h}$ be the price distortion vector of group $h$. Let $\left(p^{n} ;\left(\tau_{h}\right)_{h \in P} ; \mathbf{y}\right)$ denote a competitive equilibrium in which each nation trades in a single market place, where $\mathbf{y}$ is the equilibrium allocation, $p^{n}$ is the world market price vector and where group $h$ faces the distortion vector $\tau_{h}$ and thus the price vector $p^{n}\left(1+\tau_{h}\right)$. Then the following proposition holds:

Proposition 6 Suppose $\left(p ;\left(q_{h}\right)_{h \in P} ; \mathbf{x}\right)$ is a two-stage market equilibrium. Then there is a single market equilibrium with distortions $\tau_{h}, p^{n}=p, \mathbf{y}=\mathbf{x}$, and zero lump-sum transfers. Conversely, a single market equilibrium with zero lump-sum transfers has a corresponding two-stage market equilibrium with identical allocation and distortions.

The proof is obvious. As demonstrated by the example, the situation is in general different if we start with a single market equilibrium. Given a set of price distortions for a proper subset of groups, there are three possible cases. First, no corresponding two-stage-market equilibrium may exist. Second, endogenous price distortions for the other groups may arise and thus the allocation and distortions in the two-stage market equilibrium will differ in general from those in the one-stage market equilibrium. Third, when lumpsum transfers are zero, there exists a two-stage market equilibrium with the 
same allocation and distortions as the single market equilibrium.

We finally note that the example has the minimum number of groups to create endogenous prices distortions, i.e. such distortions can arise only if at least three groups are present. In order to show this, suppose $H=2$, with groups $h=1,2$. Let $\left(p^{n} ; \tau_{1}, \tau_{2} ; \mathbf{y}\right)$ be a single-single market equilibrium with distortions $\tau_{1}$ and $\tau_{2}$. Let $q_{1}$ and $q_{2}$ be the corresponding group price vectors. If $\tau_{2}=(0,0)$, then $q_{2}=p^{n}$ and $p^{n} \cdot\left(y_{2}-\omega_{2}\right)=q_{2} \cdot z_{2}\left(q_{2}\right)=0$. Moreover, market clearing implies $z_{1}\left(q_{1}\right)=-z_{2}\left(q_{2}\right)$. Therefore, $p^{n} \cdot\left(y_{1}-\omega_{1}\right)=p^{n} \cdot z_{1}\left(q_{1}\right)=$ $-p^{n} \cdot z_{2}\left(q_{2}\right)=0$. This shows that $\left(p^{n} ; q_{1}, q_{2} ; \mathbf{y}\right)$ shares all the properties of a two-stage market equilibrium. Hence with only two groups, trade in one market and trade in two markets lead to the same equilibria without distortionary spillovers.

\section{Conclusion}

We have developed a simple model of trade in different market places that can cause endogenous price distortions. Our findings suggest, among other things, that trade liberalization in a proper subset of countries may affect the price distortions in the remaining countries. There is a number of further issues that can be addressed within the current framework. Suppose e.g. that differences between internal and global prices are bounded, but not totally eroded by arbitrage. Then endogenous price distortions are limited which may impede the existence of two-stage market equilibria.

There remain several interesting open questions. First, how many intermediate equilibria are there in general? Specifically, if the number of commodities exceeds two, are there sufficient conditions for the existence of a continuous path from autarky to free trade? Second, how is the analysis affected by the incorporation of producers? Whereas the introduction of local producers seems to cause mainly notational complications, the modeling of 
import-export enterprises and multinational corporations constitutes a much more formidable challenge. Third, to what extent can the analysis be recast in a monetary framework? ${ }^{6}$

Here we study the allocation of commodities through a two-stage hierarchy of competitive markets. Hierarchical allocation schemes with non-market institutions at all levels have also been examined, e.g. in cooperative bargaining theory. In that context, Harsanyi (1977) points out the "joint-bargaining paradox" in the sequential application of the Nash bargaining solution. A group (coalition) of players decides to bargain first jointly for a big piece of the pie and then to bargain internally about the division of the big piece. He refers to the somewhat paradoxical phenomenon that "if two or more players form a group and act as one bargaining unit, then this will tend to weaken their bargaining position vis-à-vis the remaining players."

\footnotetext{
${ }^{6}$ For the prevalence and some consequences of limited arbitrage across monetary economies see Hens (1997).
} 


\section{References}

[1] Anderson, J.E., Bannister, G.J., Neary, J.P. (1995), "Domestic distortions and international trade", International Economic Review, Vol. 36, pp. 139-157.

[2] Bell, C. Development Policy as Public Finance, Oxford University Press, Oxford.

[3] Casella, A., Frey, B. (1992) "Federalism and clubs. Towards an economic theory of overlapping political jurisdictions" European Economic Review, Vol. 36, pp. 635-646.

[4] Dixit, A., Norman, V. (1980) Theory of International Trade: A Dual, General Equilibrium Approach, Cambridge University Press, Cambridge, MA.

[5] Ethier, W.J. (1984) "Higher dimensional issues in trade theory", Chapter 3 in Handbook of International Economics, vol. 1, edited by Jones, R.W. and Kenen, P.B., Elsevier Science Publishers (North-Holland), Amsterdam.

[6] Flam, H. (1992) "Product markets and 1992: Full integration, large gains?" Journal of Economic Perspectives, Vol. 6, pp. 7-30.

[7] Fukushima, T., Kim, N. (1989) "Welfare improving tariff changes" Journal of International Economics, Vol. 26, pp. 383-388.

[8] Gersbach, H., Haller, H. (2007) "Hierarchical Trade and Price Gaps", mimeo, August 2007.

[9] Haller, H., Holden, S. (1997) "Ratification requirements and bargaining power" International Economic Review, Vol. 38, 825-851. 
[10] Harsanyi, J.C. (1977) Rational Behavior and Bargaining Equilibrium in Games and Social Situations, Cambridge University Press, Cambridge, UK.

[11] Hatta, T., Fukushima, T. (1979) "The welfare effect of tariff rate reductions in a many country world" Journal of International Economics, Vol. 9, pp. 503-511.

[12] Hens, T. (1997) "Exchange rates and perfect competition", Journal of Economics, Vol. 65, pp. 151-161.

[13] Leamer, E., Levinsohn, J. (1995) "International Trade Theory: The Evidence", Handbook of International Economics, vol. 3, ch. 26, edited by Jones, R.W. and Kenen, P.B., Elsevier Science Publishers (NorthHolland),

[14] Lutz, M. (2004) "Pricing in segmented markets, arbitrage and the law of one price: evidence from the European car market", Review of International Economics, Vol. 12, pp. 456-475.

[15] Persson, T., Tabellini, G. (1996) "Federal fiscal constitutions: Risk sharing and moral hazard" Econometrica, Vol. 64, pp. 623-646.

[16] Putnam, R. (1988) "Diplomacy and domestic politics: The logic of twolevel games" International Organization, Vol. 42, pp. 427-460.

[17] Turunen-Red, A., Woodland, A. D. (1991) "Strict Pareto-improving multilateral reforms of tariffs" Econometrica, Vol. 59, pp. 1127-1152.

[18] Verboven, F. (1996) "International price discrimination in the European car market" Rand Journal of Economics, Vol. 27, pp. 240-268.

[19] Yun, K. (1995) "Structure of distortion equilibria and welfare in multiregional economy" Economic Theory, Vol. 5, pp. 491-512. 


\section{Working Papers of the Center of Economic Research at ETH Zurich}

(PDF-files of the Working Papers can be downloaded at www.cer.ethz.ch/research).

07/72 H. Gersabch and H. Haller Hierarchical Trade and Endogenous Price Distortions

07/71 C. Heinzel and R. Winkler The Role of Environmental and Technology Policies in the Transition to a Lowcarbon Energy Industry

07/70 T. Fahrenberger and H. Gersbach Minority Voting and Long-term Decisions

07/69 H. Gersbach and R. Winkler On the Design of Global Refunding and Climate Change

07/68 S. Valente Human Capital, Resource Constraints and Intergenerational Fairness

07/67 O. Grimm and S. Ried Macroeconomic Policy in a Heterogeneous Monetary Union

07/66 O. Grimm Fiscal Discipline and Stability under Currency Board Systems

07/65 M. T. Schneider Knowledge Codification and Endogenous Growth

07/64 T. Fahrenberger and H. Gersbach Legislative Process with Open Rules

07/63 U. von Arx and A. Schäfer The Influence of Pension Funds on Corporate Governance

07/62 H. Gersbach The Global Refunding System and Climate Change

06/61 C. N. Brunnschweiler and E. H. Bulte The Resource Curse Revisited and Revised: A Tale of Paradoxes and Red Herrings

06/60 R. Winkler Now or Never: Environmental Protection under Hyperbolic Discounting

06/59 U. Brandt-Pollmann, R. Winkler, S. Sager, U. Moslener and J.P. Schlöder Numerical Solution of Optimal Control Problems with Constant Control Delays

06/58 F. Mühe Vote Buying and the Education of a Society

06/57 C. Bell and H. Gersbach Growth and Enduring Epidemic Diseases 
06/56 H. Gersbach and M. Müller

Elections, Contracts and Markets

06/55 S. Valente

Intergenerational Transfers, Lifetime Welfare and Resource Preservation

06/54 H. Fehr-Duda, M. Schürer and R. Schubert

What Determines the Shape of the Probability Weighting Function?

06/53 S. Valente

Trade, Envy and Growth: International Status Seeking in a Two-Country World

06/52 K. Pittel

A Kuznets Curve for Recycling

06/51 C. N. Brunnschweiler

Cursing the blessings? Natural resource abundance, institutions, and economic growth

06/50 C. Di Maria and S. Valente

The Direction of Technical Change in Capital-Resource Economics

06/49 C. N. Brunnschweiler

Financing the alternative: renewable energy in developing and transition countries

06/48 S. Valente

Notes on Habit Formation and Socially Optimal Growth

06/47 L. Bretschger

Energy Prices, Growth, and the Channels in Between: Theory and Evidence

06/46 M. Schularick and T.M. Steger

Does Financial Integration Spur Economic Growth? New Evidence from the First Era of Financial Globalization

05/45 U. von Arx

Principle guided investing: The use of negative screens and its implications for green investors

05/44 Ch. Bjørnskov, A. Dreher and J.A.V. Fischer

The bigger the better? Evidence of the effect of government size on life satisfaction around the world

05/43 L. Bretschger

Taxes, Mobile Capital, and Economic Dynamics in a Globalising World

05/42 S. Smulders, L. Bretschger and H. Egli

Economic Growth and the Diffusion of Clean Technologies: Explaining Environmental Kuznets Curves

05/41 S. Valente

Tax Policy and Human Capital Formation with Public Investment in Education 
05/40 T.M. Steger and L. Bretschger

Globalization, the Volatility of Intermediate Goods Prices and Economic Growth

05/39 H. Egli

A New Approach to Pollution Modelling in Models of the Environmental Kuznets Curve

$05 / 38$ S. Valente

Genuine Dissaving and Optimal Growth

05/37 K. Pittel, J.-P. Amigues and T. Kuhn, Endogenous Growth and Recycling: A Material Balance Approach

05/36 L. Bretschger and K. Pittel

Innovative investments, natural resources, and intergenerational fairness: Are pension funds good for sustainable development?

04/35 T. Trimborn, K.-J. Koch and T.M. Steger

Multi-Dimensional Transitional Dynamics: A Simple Numerical Procedure

04/34 K. Pittel and D.T.G. Rübbelke

Private Provision of Public Goods: Incentives for Donations

04/33 H. Egli and T.M. Steger

A Simple Dynamic Model of the Environmental Kuznets Curve

04/32 L. Bretschger and T.M. Steger

The Dynamics of Economic Integration: Theory and Policy

04/31 H. Fehr-Duda, M. de Gennaro, R. Schubert

Gender, Financial Risk, and Probability Weights

03/30 T.M. Steger

Economic Growth and Sectoral Change under Resource Reallocation Costs

03/29 L. Bretschger

Natural resource scarcity and long-run development: central mechanisms when conditions are seemingly unfavourable

03/28 H. Egli

The Environmental Kuznets Curve - Evidence from Time Series Data for Germany

03/27 L. Bretschger

Economics of technological change and the natural environment: how effective are innovations as a remedy for resource scarcity?

03/26 L. Bretschger, S. Smulders

Sustainability and substitution of exhaustible natural resources. How resource prices affect long-term R\&D-investments

03/25 T.M. Steger

On the Mechanics of Economic Convergence 